\title{
DE STATUIS: LAS FUENTES CRISTIANAS SOBRE LA “REVUELTA DE LAS ESTATUAS”
}

\author{
POR \\ Alberto J. QUiRoga Puertas* \\ Universidad de Granada \\ aquiroga@ugr.es
}

\begin{abstract}
RESUMEN
La información sobre la "Revuelta de las estatuas" acontecida en Antioquía en el año 387 d. C. transmitida por autores cristianos contemporáneos a la asonada y del siglo $\mathrm{V}$ d. C. relata los acontecimientos desde diversos géneros literarios pero con unas líneas directrices comunes. La decisiva intervención del sector meleciano de la Iglesia antioquena para conseguir el perdón del emperador Teodosio y el retrato de éste como un monarca obediente a las figuras cristianas son las pautas comunes en los relatos de Juan Crisóstomo, Ambrosio de Milán, Sozómeno y Teodoreto de Ciro.
\end{abstract}

PALABRAS CLAVE: Antioquía; Literatura cristiana; Cisma meleciano; Emperador Teodosio.

\section{DE STATUIS: CHRISTIAN SOURCES ON THE“RIOT OF STATUES”}

\begin{abstract}
The historical account of the "Riot of the Statues" of A.D. 387 Antioch found in Christian authors coetaneous to the event and from the Vth century A.D. is provided from different literary genres but approached with common narrative lines. The decisive intervention of the Meletian group of the Antiochene Church in order to obtain the emperor Theodosius' forgiveness and his portrait as a submissive ruler to Christian figures are the main leitmotifs in the accounts of John Chrysostom, Ambrose of Milan, Sozomenus and Theodoretus of Cyr.
\end{abstract}

KEY WORDS: Antioch; Christian Literature; Meletian Schism; emperor Theodosius.

$\begin{array}{lc}\text { Recibido/Received } & \text { 24-01-2013 } \\ \text { Aceptado/Accepted } & 13-02-2014\end{array}$

El presente trabajo pretende analizar las estrategias de orden político, religioso y eclesiástico que reflejan las fuentes cristianas relativas a la "Revuelta de las estatuas" acaecida en el año 387 en Antioquía. A pesar de la dificultad para establecer un relato fidedigno de este acontecimiento, dada la diversa y diferente información transmitida por las dos fuentes principales -el sofista pagano Libanio de Antioquía (Disc. 19-23) y Juan Crisóstomo (XXIV Homilías sobre las estatuas)-, ${ }^{1}$ es posible esbozar un resumen relativamente

Quisiera expresar mi agradecimiento al Prof. Fernández Ubiña y a los revisores de este artículo sus sugerencias y correcciones. Este trabajo se enmarca en el proyecto de investigación FFI2012-32012 "La teatralización de la retórica y el establecimiento de un canon en la literatura griega y latina en la Antigüedad tardía (s. III-V)", del Ministerio de Economía, Industria y Competitividad.

1 Frente a la frecuente atribución de 21 homilías al corpus de Crisóstomo, adopto la hipótesis de un corpus de 24 siguiendo a certero de lo acontecido. ${ }^{2}$ La precaria situación económica de la ciudad, unida a un ambiente levantisco provocado por varias revueltas en los años anteriores (354, 362-363, $371-372,382-385)$, propició que, tras la lectura de un decreto que anunciaba la imposición de un impuesto inesperado, los curiales y honorati de la ciudad se manifestaran

Valedicius, A. 2000. “Les 24 homélies De Statuis de Jean Chrysostome. Recherches nouvelles". Revue des Études Augustiniennes et Patristiques 46: 83-91.

2 La reconstrucción más completa de los hechos es el estudio de van der Paverd, F. 1991. St. John Chrysostom. The homilies on the Statues: 15-159. Roma: Institutum Studiorum Orientalium. Veáse también Malosse, P.L. 2007. “Comment arrêter un massacre: une leçon de rhétorique appliquée (Libanios, Discours XIX)". Revue des Études Grecques 120: 107-140; Petit, P. 1955. Libanius et la vie municipale à Antioche au IVe siècle après J.C: 238-244. París: Geuthner; Quiroga Puertas, A.J. 2007. La retórica de Libanio y de Juan Crisóstomo en la revuelta de las estatuas: 9-17. Salerno: Helios. 
espontáneamente contra tal exacción. ${ }^{3}$ A este grupo se fueron uniendo cada vez más antioquenos y miembros de la claque teatral, ${ }^{4}$ provocando incidentes violentos que desembocaron en la destrucción de los paneles en los que aparecía el retrato de la familia imperial y en el derribo de las estatuas que representaban al emperador Teodosio, a su mujer, Flacila, a su padre, Teodosio, y a sus hijos Honorio y Arcadio. ${ }^{5}$ Las fuerzas militares bajo el mando del comes Orientis apaciguaron la revuelta, tras la cual parte de la población antioquena huyó ante los castigos que podría imponer el emperador Teodosio, que mandó dos emisarios para que investigaran y evaluaran lo sucedido: Cesario, que ocupaba entonces el cargo de magister officiorum, y Elébico, magister militum. Mientras tanto, uno de los obispos de Antioquía, Flaviano, viajó a Constantinopla junto con una representación de los curiales de la ciudad siria para intentar conseguir el perdón de Teodosio. Tras los juicios y pesquisas pertinentes, Cesario regresó a Constantinopla para informar al emperador, quien decidió perdonar a la ciudad, paralizar las ejecuciones y anular los castigos parciales que había impuesto -arrestos y ejecuciones sumarias, cierre de los baños públicos, teatro e hipódromo; encarcelamiento de la clase curial; degradación del rango de ciudad "metrópolis" de Antioquía, que fue provisionalmente transferido a Laodicea. ${ }^{6}$

3 Sobre la naturaleza (la crítica moderna duda entre una lustralis collatio o una superindictio que gravaría a los possesores) y finalidad del impuesto, vid. Chadwick, H. 2001. The Church in Ancient Society. From Galilee to Gregory the Great: 479. Oxford: Oxford University Press; De Sainte Croix, G.E.M. 1988. La lucha de clases en el mundo griego antiguo: 257-258. Barcelona (trad.): Crítica; Depeyrot, G. 1996. Crisis e inflación entre la Antigüedad y la Edad Media: 22. Barcelona (trad.): Crítica; King, N.Q. 1961. The Emperor Theodosius and the establishment of Christianity: 60. Londres: SCM; Liebeschuetz, J.H.G.W. 1959. "The finances of Antioch in the fourth century". Byzantinische Zeitschrift, 52.2: 344, 355; Petit, P. 1955: 145-146; Rostovtzeff, M. 1973. Historia Social y Económica del Imperio Romano: 451, 465-466. Madrid (trad.): Espasa; van der Paverd, F. 1991: 19-20.

4 Sobre la participación de la claque teatral, vid. Browning, R. 1952. "The riot of A.D. 387 in Antioch. The role of the theatrical Claques in the Late Empire". Journal of Roman Studies 42: 16-18; Leppin, H. 1999. "Steuern, aufstand und rhetoren: der antiochener steueraufstand von 387 in christlicher und heidnischer deutung", en Brandt, H. (ed.), Gedeutete Realität. Krisen, wirklichkeiten, interpretationem (3.-6. Jh. n.Chr.): 114. Stuttgart: F. Steiner; Liebeschuetz, J.H.G.W. 1972. Antioch: city and imperial administration in the later Roman Empire: 215. Oxford: Oxford University Press. Para una opinión contraria, vid. Petit, P. 1955: 241; van der Paverd, F. 1991: 31, 33.

Stewart, P. 1999. "The destruction of Statues in Late Antiquity", en Miles, R. (ed.), Constructing Identities in Late Antiquity: 164-167. Londres: Routledge, ha tipificado un esquema habitual del decurso de estos acontecimientos y que puede seguirse en el caso de la revuelta de las estatuas de Antioquía atendiendo al relato del sofista Libanio: cantos críticos contra la autoridad imperial (Lib., Or. XIX, 28); derribo de la estatua y posterior mutilación y arrastramiento de la figura (Or. XIX, 29; XXII, 8). El único punto de desencuentro es la desaparición final de las estatuas, algo que no ocurrió en Antioquía, ya que Juan Crisóstomo Hom. XVII, PG 49, 173 nos informa de que fueron restauradas y restituidas. En cuanto a los paneles de madera, vid. Bruun, P. 1976. "Notes in the transmission of Imperial Images in Late Antiquity", en Ascani, K. et al. (eds.), Studia Romana in Honorem Petri Krarup septuagenarii: 124-126. Odense: Odense University Press; Downey, G. 1962. Antioch in the age of the Theodosius the Great: 124125. Oklahoma: University of Oklahoma Press.

6 Sobre las implicaciones y consecuencias de esta degradación, vid. Brown, P. 1992. Power and Persuasion in Late Antiquity. Towards a Christian Empire: 11, 18. Madison: University of Wisconsin Press;
Esta revuelta aconteció en una Antioquía que sufría las consecuencias del "cisma meleciano", cuyo origen se sitúa en la deposición del obispo niceno Eustacio por sus enfrentamientos con Eusebio de Nicomedia tras la celebración del concilio de Nicea. ${ }^{7}$ Como consecuencia de esta disputa, la Iglesia antioquena quedó dividida en tres grupos: los fieles al depuesto Eustacio -quienes quedaron bajo el control de Paulino-, un pequeño grupo arriano y un sector de nicenos bajo la tutela de Eufronio, Diodoro y Flaviano. El ambiente cismático empeoró con el nombramiento de Melecio como obispo de la capital siria en el sínodo de Antioquía (invierno 360-361), especialmente porque Melecio fue exiliado hasta en tres ocasiones debido a su ambigua posición doctrinal y a sus desavenencias con los emperadores arrianos Constancio Il y Valente (si bien contó con el apoyo de los emperadores Juliano y Joviano). Cuando se le permitía permanecer en Antioquía, Melecio debía competir por ser el único y legítimo obispo antioqueno con el arriano Euzoio, el apolinarista Vitalis y el niceno Paulino, al tiempo que debía ganarse el respeto de las influyentes sedes de Roma y Alejandría, que apoyaban a Paulino.

El mandato de Teodosio tuvo un marcado signo positivo para Melecio, ya que el emperador lo escogió para presidir el concilio de Constantinopla (381). Además, según algunos autores como Gregorio de Nacianzo (De vita sua, vv. 1571-1586), consensuó con Paulino, su rival dentro del nicenismo, una solución para poner fin al cisma: el obispo que sobreviviera al otro se haría cargo de toda la comunidad nicena de Antioquía. Sin embargo, tras la muerte de Melecio su facción no respetó el acuerdo alcanzado e impuso a Flaviano como obispo de Antioquía en lugar de ceder el cargo a Paulino. Esta nueva causa de discordia aún persistió tras la muerte de Paulino, por lo que el cisma no finalizó hasta que el segundo sucesor de Flaviano, Alejandro, unió las facciones nicenas de Antioquía en el $415 .^{8}$ No extraña, por lo tanto, que Juan Crisóstomo se lamentara de la situación del cristianismo en la capital siria a finales del siglo IV: "La oscuridad cae no sólo sobre los heréticos y los paganos, sino también sobre muchos de nosotros debido a los dogmas y al estilo de vida: muchos creen en la resurrección, otros se levantan contra su nacimiento, muchos están al tanto de observaciones con

Will, E. 2000. "Antioche, la métropole de l'Asie”, en Nicolet, C.; Ilbert, R. y Depaule, J.C. (eds.), Mégapoles méditerranéennes. Géographie urbaine rétrospective: 482. París: Maissonneuve et Larose.

La bibliografía moderna ubica la fecha de deposición entre el 326 y el 331, vid. Cavallera, F. 1905. Le schisme d'Antioche: 33-41. París: A. Picard; Chadwick, H. 2001: 415; Sotomayor, M. 2003. "El cristianismo en Oriente", en Fernández Ubiña, J. y Sotomayor, M. (eds.), Historia del Cristianismo: 817. Madrid: Trotta.

Sobre el cisma meleciano, vid. Cavallera, F. 1905; Downey, G. 1961. A History of Antioch in Syria: from Seleucus to the Arab Conquest: 410-411. Princeton: Princeton University Press; Chadwick, H. 2001: 415-432; García Fernández, J.M. 1995. "La autocefalia de la Iglesia chipriota, una consecuencia del cisma del siglo IV en la cristiandad de Antioquía". Espacio, Tiempo y Forma Serie II, Ha. Antigua 8: 501-505; Pietri, C. 1993. "Les dernières résistances du subordinatianisme et le triomphe de l'orthodoxe nicéenne", en Mayeur, J.M. (ed.), Histoire du Christianisme: 357-398. París: Desclee; Sotomayor, M. 2003; Spuntarelli, C. 2010. "Didascalia e potere episcopale ad Antiochia nell' ideologia dei panegirici di Giovanni Crisostomo". ASE 27.1: 77-100. Vid. Socrates Escolástico HE 2.44, 4.2 y 4.17 para testimonios sobre Melecio y las disputas en el seno de la Iglesia de Antioquía. 
presagios, augurios y cálculos, y hay otros que emplean amuletos y ensalmos". ${ }^{9}$

Ya en un trabajo anterior destaqué que las fuentes cristianas relativas a la revuelta de las estatuas aprovecharon la asonada para exponer una estrategia conjunta de defensa de la facción meleciana de la iglesia antioquena. Autores como Juan Crisóstomo, Ambrosio de Milán, Sozomeno y Teodoreto de Ciro aludieron a la revuelta en distintas obras que comparten un núcleo narrativo e ideológico con el objetivo de posicionarse claramente a favor del grupo meleciano en el marco de las disputas internas que afectaron a la iglesia de Antioquía durante buena parte del siglo IV. Este artículo tiene, por lo tanto, un doble objetivo. En primer lugar, analizar la información relativa a la revuelta de las estatuas consignada en tales fuentes cristianas, y examinar los intereses políticos y religiosos del relato de cada autor. En segundo lugar, evaluar las concordancias temáticas y acuerdos ideológicos entre las distintas fuentes como parte de una estrategia de carácter religioso (orquestación y ejecución literaria de un "plan meleciano") y político (establecimiento de una nueva relación de poder entre el orden eclesiástico y el emperador).

\section{DE STATUIS: LAS HOMILÍAS DE JUAN CRISÓSTOMO}

La información que transmiten las homilías de Juan Crisóstomo relativas al desarrollo de los acontecimientos de la revuelta se puede catalogar en dos grupos. En primera instancia, Crisóstomo aporta información sobre la situación en Antioquía tras la revuelta en la medida en que el relato de esos hechos sirve para evidenciar la utilidad y supremacía del cristianismo como consuelo espiritual frente a instituciones terrenales. ${ }^{10}$ La pericia retórica de Juan Crisóstomo convirtió la narración de las ejecuciones y el miedo a los juicios y a las represalias del emperador Teodosio en elementos narrativos de carácter proselitista al servicio de la causa cristiana (Hom. II, PG 49, 35-36; III PG 49, 55; VI, PG 49, 82). De este modo, es reseñable el hecho de que Crisóstomo disertara sobre el solaz espiritual que los antioquenos encontrarían en la iglesia frente a las preocupaciones mundanales de otros lugares (Hom. X, PG 49, 111-112): "Si vas al tribunal, allí encontrarás disputas y peleas; si vas a la curia, la preocupación por los asuntos públicos; si a una casa, constriñe por todas partes la preocupación por los asuntos particulares; si a las reuniones y asambleas del ágora, allí también todo es terrenal y corruptible. Pues todo lo que hablan los que allí se reúnen es o acerca de compras, o acerca de contribuciones,

9 In epistulam I ad Corinthios, Hom. IV.11 (PG 61, 38). Traducción tomada de Quiroga Puertas, A.J.. 2007: 95. Desafortunadamente, la única edición del texto griego de gran parte del corpus homilético de Juan Crisóstomo es la de B. de Montfaucon contenida en la Patrologia Graeca.

10 Sobre la conversión de "semi-cristianos" gracias a las homilías de Crisóstomo, vid. Brottier, L. 2004. "Jean Chrysostome. Un pasteur face à des demi-chrétiens": 439-457. Topoi Suppl. 5; Soler, E. 1997. "Evêque et pasteurs à Antioche sous l'empereur Théodose: l'engagement chrétien dans la défense de la cité après la séditions des statues (387)", en Istituto Patristico Augustinianum (ed.), Vescovi e pastori in época Teodosiana. XXV Incontro di studiosi dell'antichità cristiana: 462-463. Roma: Istituto Patristico Augustinianum. Sobre la conversión al cristianismo a raíz de la intervención cristiana en la revuelta de las estatuas, vid. el Sobre Ana de Crisóstomo. o acerca de las magníficas mesas, o acerca de la venta de terrenos, o acerca de otras transacciones, o acerca de testamentos, o acerca de herencias, o acerca de otros asuntos por el estilo. Y si vas a las estancias del palacio imperial, también allí escucharás de nuevo lo mismo, puesto que todos hablan de dinero, de poder, de la gloria aquí venerada, pero nada espiritual. En cambio, aquí todo lo contrario: acerca del cielo y sus asuntos, acerca del alma, acerca de nuestra vida, y para qué hemos nacido, y por qué pasamos en esta vida tanto tiempo, y hacia dónde viajamos desde aquí, y qué nos sucederá tras esta vida, y por qué motivo nuestro cuerpo es de arcilla, y cuál es la naturaleza de la muerte, y, finalmente, qué es la vida presente y qué la futura. En una palabra, nada hay terrenal, sino que todo lo que se dice versa sobre lo espiritual y poniendo grandes remedios para nuestra salvación, saldremos de aquí con virtuosa esperanza". ${ }^{11}$

En este mismo sentido, la tensa situación en Antioquía influyó en la mezcla de páthos retórico ${ }^{12}$ y admoniciones morales que marcó el relato de Crisóstomo de los juicios (Hom. XIII, PG 49, 135-137): "Yo estaba al lado y veía que las mujeres y las jóvenes casaderas constituían un espectáculo común para todos. Incluso las que se acostaban en tierno lecho tenían el suelo como cama, y las que disfrutaban de un gran séquito de sirvientes, eunucos y de todas las restantes muestras de apariencia, desprovistas ahora de todo aquello se arrastraban ante los pies de todos, pidiendo a cada cual que en algo auxiliaran a los que iban a ser juzgados, y que hubiera un común sentimiento de misericordia por parte de todos. Yo dije lo de Salomón: Vanidad de vanidades, y todo vanidad. Pues veía que esto era lo que ocurría, y que otra juiciosa máxima venía a cuento de los acontecimientos: Toda opinión del hombre es como el heno: se seca el heno, y la flor cae". Tales textos encontraron su réplica en la principal fuente pagana de la revuelta del año 387, los discursos 19-23 del sofista antioqueno Libanio de Antioquía. Estos discursos, compuestos una vez que el emperador Teodosio concedió el perdón a la ciudad, constituyen una respuesta a parte de la argumentación de las homilías de Crisóstomo. La defensa de las virtudes de raigambre pagana así como la defensa de un modelo cívico tradicional por parte del sofista forma parte de un proceso de intertextualidad entre las homilías de Juan Crisóstomo y los discursos de Libanio que subraya el valor estratégico y político que tuvo la defensa de Antioquía tras la revuelta. ${ }^{13}$

11 Este texto se puede interpretar como parte de la estrategia retórica de Crisóstomo para marcar el contraste entre enclaves y conceptos cristianos frente a aquellos meramente civiles, vid. Liebeschuetz, J.H.W.G., Ambrose and John Chrysostom. Clerics between Desert and Empire: 214-215. Oxford: Oxford University Press; Shepardson, C. 2007. "Controlling Contested Places: John Chrysostom's Adversus Iudaeos Homilies and the Spatial Politics of Religious Controversy". Journal of Early Christian Studies 15.4: 483516. Una buena síntesis del sustrato y presencia cultural cristiana en Antioquía en Ashbrook-Harvey, S. 2000. "Antioch and Christianity", en C. Kondoleon (ed.), Antioch, The Lost Ancient City: 43-49. Princeton: Princeton University Press.

12 Wisse, J. 1989. Ethos and Pathos from Aristotle to Cicero: 6574. Amsterdam: Hakkert.

13 Sobre la importancia de este procedimiento intertextual, vid. Maxwell, J. 2006. Christianization and Communication in Late Antiquity. John Chrysostom and his Congregation at Antioch: 60-61. Cambrige: Cambridge University Press. Quiroga Puertas, A.J. 2007: 125-160; 2014: 74-85. 
En segundo lugar, los textos de Crisóstomo relativos a la revuelta reflejan una actitud propagandística a favor del grupo meleciano en el marco del cisma antioqueno. En este sentido, destacan los relatos de las acciones a favor de la ciudad que emprendieron los monjes que vivían en los alrededores de Antioquía ${ }^{14}$ y la narración de la embajada del obispo Flaviano ante el emperador Teodosio en Constantinopla. En cuanto a la actuación de los monjes, Crisóstomo alaba su intervención ante los emisarios imperiales (Hom. XVII, PG, 49, 172-173): "Pues cuando los emisarios del emperador organizaron aquel temible tribunal para investigar lo sucedido, citaron a todos para rendir cuentas por las osadías y todos temían distintos tipos de muertes, los monjes que habitaban las cimas de los montes demostraron entonces su particular estilo de vida. En efecto, los que habían estado encerrados juntos durante tantos años en sus cuevas, sin que nadie les llamara, sin que nadie se lo aconsejara, cuando vieron la nube tan grande que cercaba la ciudad, abandonaron sus cuevas y cavernas y concurrieron de todas partes como ángeles venidos del cielo. $Y$ entonces se podía ver la ciudad parecida al cielo, con aquellos santos por todas partes, que con su sola visión consolaban a los que sufrían y los conducían a un total desprecio de la desgracia. ¿Quién no se habría reído de la muerte al ver a aquellos? ¿Quién no habría menospreciado la vida?".

Especial atención merece, en mi opinión, el relato de la embajada del obispo Flaviano ante el emperador Teodosio, dado que forma parte de una estrategia política de largo recorrido en la tradición literaria cristiana posterior para presentar a Flaviano como el único obispo legítimo de Antioquía en el marco del cisma meleciano. Es este contexto de divisiones internas el que provee las claves de lectura de los pasajes relativos a la intervención del obispo Flaviano en la revuelta de las estatuas. Así, Crisóstomo prefirió no inmiscuirse en cuestiones teológicas ni dar un tratamiento doctrinal al cisma, sino apoyar la causa meleciana de forma propagandística mediante un retrato casi hagiográfico de los méritos de Flaviano con el fin de ganar adeptos a la causa meleciana entre los antioquenos. ${ }^{15}$ De hecho, dentro de la vastísima producción de Juan Crisóstomo, se puede hablar de un periodo de propaganda meleciana que incluiría otras obras de marcado tinte retórico que trascienden la faceta religiosa y se inmiscuyen en la disputa por el poder religioso en Antioquía. ${ }^{16}$

Es a la luz de este contexto religioso y de la grave situación política como hay que interpretar la narración de la embajada del obispo Flaviano ante el emperador Teodosio en Constantinopla en las homilías 3, 17 y, especialmente, 21

\footnotetext{
14 Sobre la procedencia, dedicación y naturaleza de la comunidad de esos monjes, vid. van der Paverd, F. 1991: 266-288.

15 El cisma meleciano es referido en clave metafórica en algunas homilías de Crisóstomo, ya que quería evitar mencionarlo explícitamente y dar la impresión de una iglesia antioqueno unida. Vid. Guinot, J.N., 2001. "L'Histoire du siège d'Antioche relue par Jean Chrysostome. Idéalisation ou déformation intentionelle?", en Cabouret, B.; Gatier, P.L. y Saliou, C. (eds.), Antioche de Syrie. Histoire, images et traces de la ville Antique: 461. Lyon: De Boccard.

16 Sermo cum presbyter ordinatus, In genesim sermo I, In ascensionem, Ad Meletium, Ad Eustachium. Las fechas dadas para estas composiciones en Mayer, W. 2005. The homilies of St. John Chrysostom, provenance: reshaping the foundations: 51, 80. Roma: Pontificio Istituto orientale son cercanas al 387.
}

del corpus De Statuis. En un pasaje programático, el viaje de Flaviano es relatado por Crisóstomo de la siguiente manera (Hom. III, PG 49, 47): "Pues cuando escuchó: El buen pastor expone su vida por su rebaño, él marchó para exponer su vida por todos nosotros, aunque muchas cosas se lo impedían y le obligaban a permanecer. En primer lugar, su edad, que se prolongaba hasta una extrema vejez; luego, la debilidad de su cuerpo, y la estación del año, y la premura de la santa fiesta. Además de ello, su única hermana se hallaba en sus últimos estertores. Sin embargo, obvió el parentesco, su vejez, su debilidad, lo inoportuno de la ocasión y la dificultad del camino, y tras anteponeros a vosotros y vuestra salvación a todo eso, rompió con todas esas ataduras, y, como un joven, el anciano marcha hacia delante, con alas por su buen corazón". La recepción de este relato debió ser amplia, ya que en el discurso 19 de Libanio de Antioquía el sofista se describe de manera similar en su oneroso pero ficticio viaje a Constantinopla para persuadir al emperador (Disc. 19.1-3).

Ya en el palacio imperial en Constantinopla, Crisóstomo prosigue con la narración del episodio deteniéndose en el aspecto más teatral del discurso de Flaviano. La sólida formación literaria y cultural de Crisóstomo se deja notar en el conocimiento de los preceptos de la actio retórica y en los medios persuasivos no verbales para conseguir la captatio benevolentiae del emperador (Hom. XXI, PG 49, 214): "Cuando llegó a aquella gran ciudad y entró en las estancias imperiales, se colocó lejos del emperador, mudo, llorando, con la cabeza gacha, ocultándose, como si hubiera sido él quien hubiera cometido todo aquello. Así se comportaba, porque quería conmoverle hasta la compasión primero con su aspecto, sus ojos, sus llantos, y luego iniciar nuestra defensa. Pues el único perdón que queda para los pecadores es callar y no decir nada en defensa de lo ocurrido". ${ }^{17} \mathrm{La}$ obtención del perdón por parte de Teodosio es, en el relato de Crisóstomo, la consecuencia lógica de la intervención de Flaviano y no de las autoridades imperiales, como podría desprenderse de la lectura de los discursos 21-22 de Libanio (Hom. XXI, PG 49, 211-212): "En efecto, la ciudad fue honrada: cuando le sobrevinieron tales peligros, dejó de lado a todos los poderosos, a los que rebosan grandes riquezas, a los que tienen gran influencia ante el emperador, y se ha refugiado en la Iglesia y en el sacerdote de Dios, y con gran fe en el cielo se ha adherido a la esperanza".

Las homilías de Crisóstomo, por lo tanto, reposan sobre una cuidada planificación con el objetivo de ensalzar la figura del obispo Flaviano, cabeza visible de la facción meleciana, como valedor de la salvación de Antioquía. La parrhesía ${ }^{18}$ de la que dota Crisóstomo a Flaviano en su intervención ante Teodosio es tal que en un pasaje de la homilía XXI el obispo establece un silogismo retórico (Hom. XXI, PG 49, 215): si Teodosio castiga a Antioquía y arrasa la ciudad, estará llevando a cabo lo planeado por el demonio

17 Vid. Cic., Inven. 1.15 y Quint., Inst. Or. 4.1.40-41 para los tipos de exordio y los preceptos a seguir en caso de pronunciar un discurso en circunstancias desfavorables. Sobre las estrategias retóricas de Crisóstomo en el marco general de la oratoria y la retórica cristiana, vid. Auski, P. 1995. The Evolution of a Spiritual Idea. Christian Plain Style: 139-141, 171-173. Montreal: McGill-Queen's University Press.

18 Sobre la parrhesía cristiana en el ámbito político, son muy interesantes las reflexiones de Rapp, C. 2005. Holy Bishops in Late Antiquity: the nature of Christian leadership in an age of transition: 270-272. Berkeley: University of California Press. 
que instigó la algarada ya que la ciudad siria fue atacada por la fuerza diabólica a causa de ser la más querida por el emperador. Veladamente, por lo tanto, Flaviano advierte a Teodosio que si no depone su ira se convertirá en un instrumento de Satán. La habilidad retórica de Crisóstomo, tanto en su aspecto verbal como en la representación de una actio retórica apropiada a las circunstancias, se puso al servicio del obispo Flaviano en una serie de homilías que sirvieron como propaganda de la facción meleciana. Así lo sostiene E. Soler, quien considera que las homilías De Statuis constituyeron una estrategia literaria de la facción meleciana: "Elles présentent aussi l'intérêt de montrer, à travers le discours chrysostomien, la position de l'Eglise chrétienne dominante à Antioche, c'est-à-dire l'Eglise qui a la mainmise sur les lieux de culte chrétiens de la cité, Eglise à laquelle Saint Jean Chrysostome appartient. Cette Eglise est niceenne et même, pourrions nous dire, mélétienne (...) Il est absolument nécessaire de replacer la sédition des Statues et ses suites dans le contexte historique du schisme d'Antioche et d'examiner à travers les homélies de Saint Jean Chrysostome comment les partisans de Flavien ont mis en place toute une stratégie de représentation et de défense de la cité". ${ }^{19}$ Igualmente, según C. Spuntarelli, hay que acercarse a la producción encomiástica de Juan Crisóstomo teniendo en mente que éste quiso defender a Flaviano como el único obispo legítimo de Antioquía. Así, en sus elogios a Ignacio de Antioquía, Eustacio y Melecio, Juan Crisóstomo intentó "tracciare un'ininterrotta línea di continuità nell'episcopato di Antiochia che va da Pietro a Flaviano passando per Ignazio, Eustazio e Melecio". ${ }^{20}$

Así pues, tanto la intervención del obispo Flaviano como el testimonio de la acción de los monjes que habitaban los montes cercanos a Antioquía conforman un relato políticoreligioso de la revuelta con el que Juan Crisóstomo pretendía presentar a la sección meleciana ${ }^{21}$ de la iglesia antioquena como la legítima salvadora de la ciudad en unas circunstancias especialmente difíciles.

\section{AMBROSIO dE MILÁN (EP. 74)}

Una muy breve alusión a la revuelta de las estatuas se encuentra en la peroración de una larga epístola enviada por Ambrosio de Milán al emperador Teodosio a propósito de la destrucción de una sinagoga y un lugar de reunión de la secta de los Valentinianos a manos de unos monjes de Calínico en el invierno de 388-389. Aunque en un principio el emperador exigió al comes Orientis que obligara al obispo local a reconstruir la sinagoga e investigar sobre lo acontecido, Teodosio finalmente se retractó de su decisión. Así, en una carta escrita tras la ulterior decisión del emperador, Ambrosio conminaba al emperador a que perdonara los actos violentos de los monjes del mismo modo que había perdonado a Antioquía tras la revuelta -Ep. 74.32: Antiochenis, tuam

19 Soler, E. 1997: 462.

20 Spuntarelli, C. 2010: 79. Vid. Pan. Eust. 4 (PG 50, 597-606) y Pan. Melet. 2 ( $P G 50,515-520)$. También Soler, E. "Utilisation de I'historie de l'Église d'Antioche au IVème siècle par Jean Chrysostome dans les débuts de sa prédication”, en B. Pouderon y Y. M. Duval (eds.), L'Historiographie de l'Église des premiers siècles: 499-510. París: Beauchesne.

21 Soler, E. 1997: 465-466. donasti iniuriam-. A pesar de la brevedad de la referencia contenida en la carta de Ambrosio, ésta es importante por dos motivos. En primer lugar, certifica que la revuelta fue anterior al año 388 (fecha del episodio que motivó la composición de la misiva), a pesar de que otra fuente de la revuelta, Teodoreto de Ciro, la situara tras la masacre de Tesalónica ordenada por el emperador Teodosio en el 390. ${ }^{22}$ En segundo lugar, esta carta revela uno de los motivos recurrentes en las fuentes cristianas a propósito de la revuelta: el papel del emperador Teodosio ante la presión de figuras episcopales de gran influencia como el obispo Flaviano o el propio Ambrosio de Milán. En el caso de la carta de Ambrosio, se trata de un pulso político al emperador por parte del obispo de Milán ya que la carta, compuesta una vez que Teodosio se había retractado de su decisión inicial de forzar al obispo de Calínico a que reconstruyera la sinagoga, fue redactada con un fingido desconocimiento de la decisión final del emperador (Ep.74.1-8), lo que convirtió su publicación en un acto de presión política para dejar a las claras la influencia del poder eclesiástico sobre el emperador. De hecho, esta disposición de Ambrosio se ve refrendada por unas últimas líneas de tono amenazante (Ep. 74.33: ut me magis audires in regia, ne si necesse esset audires in ecclesia). ${ }^{23}$

\section{SOZÓMENO. HE VII.23}

En el caso de la Historia Eclesiástica de Sozómeno, las líneas que dedica el historiador al relato de la revuelta de las estatuas representan fielmente el espíritu de la historiografía cristiana tardo-antigua. En este sentido, hay dos aspectos principales a destacar en Sozómeno HE VII.23. En primer lugar, el historiador introduce un elemento nuevo en la secuencia de acontecimientos respecto a la narrativa de las homilías de Juan Crisóstomo. Según Sozómeno, no fue la elocuencia del obispo Flaviano lo que consiguió persuadir al emperador para que concediera el perdón a la ciudad siria, sino que a petición del obispo fueron unos jóvenes que entonaron himnos litúrgicos propios de Antioquía los que convencieron al emperador para que depusiera su ira. ${ }^{24} \mathrm{En}$ mi opinión, la introducción de este elemento novedoso en la narrativa de la embajada de Flaviano tiene como objetivo enfatizar su status como único obispo legítimo de Antioquía y la consideración de Teodosio como emperador defensor del nicenismo ortodoxo. ${ }^{25}$ Considero que esta innovación

\footnotetext{
22 Sobre los motivos y explicación de esta cronología en Teodoreto, vid. infra.

${ }^{23}$ Sobre las implicaciones políticas de este episodio, vid. el estudio y traducción de Liebeschuetz, J.H.W.G. y Hill, C. 2005. Ambrose of Milan. Political Letters and Speeches: 95-123. Liverpool: Liverpool University Press; Liebeschuetz, J.H.W.G. 2011: 91-94; McLynn, N. 1994. Ambrose of Milan. Church and Court in a Christian Capital: 298307. Berkeley: University of California Press; Natal Villazala, D. 2010. Fugiamus ergo forum. Ascetismo y poder en Ambrosio de Milán: 166169. León: Universidad de León.

24 Sozómeno HE VII.23.

25 King, N.Q. 1961: 61-69; Thélamon, Fr. 2010. “Théodose, l’État et les religions", en Delage, P.-G. (ed.), Ambroise de Milan et les défis du politique: 25-56. Royan: Caritas Patrum. Sobre la consolidación de las medidas religiosas constantinianas por parte de Teodosio, vid. Buenacasa, C. 1997. "La figura del obispo y la formación del patrimonio de las comunidades cristianas según la legislación imperial del reinado de Teodosio I". Studia Ephemeridis Augustinianum 58.1: 121-139.
} 
adquiere pleno sentido en el relato de Sozómeno si tenemos en cuenta que, según el historiador, cuando Flaviano partió hacia Antioquía, dejó a la población suplicando y dedicando himnos a Dios para que inspirara al emperador a que depusiera su ira. Creo que el hecho de que Sozómeno se desvíe de la estrategia de persuasión empleada por Flaviano en el relato de Crisóstomo es una licencia literaria con importantes implicaciones políticas y religiosas, ya que la reproducción de las letanías e himnos antioquenos dedicados a Dios en la corte de Constantinopla era un elemento que presionaba al emperador Teodosio para que se hiciera responsable de las vidas de los ciudadanos de Antioquía. Como destinatario de tales himnos, él no podría dejarse llevar por una pasión humana como la ira, sino actuar con perdón divino. ${ }^{26}$

En segundo lugar, Sozómeno no sólo retoma la explicación de Libanio y Juan Crisóstomo según la cual un daímon maligno fue el verdadero instigador de los acontecimientos violentos, ${ }^{27}$ sino que refuerza el recurso a lo sobrenatural al introducir la aparición del fantasma de una mujer gigante. El historiador (HE VII.23) relata que la noche anterior a la revuelta una figura fantasmal, de tamaño gigante y que hacía restañar un látigo, se dejó ver por las calles de Antioquía. En mi opinión, la caracterización de este fantasma se corresponde con los atributos y el ámbito de acción de la diosa Hécate:28 el tamaño gigante de Hécate aparece testimoniado en papiros mágicos (PGM IV.2711); el hecho de que el fantasma aparezca errando por las calles de Antioquía recuerda

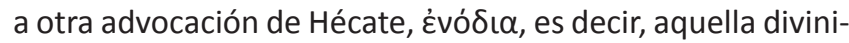
dad que aparece en las calles y encrucijadas, ${ }^{29}$ igualmente, el látigo que restalla el fantasma es un objeto que aparece en la iconografía de esta diosa; ${ }^{30}$ finalmente, el sincretismo y solapamiento de Hécate con divinidades relacionadas con el mundo del Más Allá está bien atestiguado. ${ }^{31} \mathrm{~A}$ pesar de

26 Sobre la influencia de los factores religiosos en la toma de decisiones por parte de Teodosio, vid. Maraval, P. 2009. Théodose le Grand: le pouvoir et la foi: 305-309. París: Fayard.

27 Sobre el uso de Juan Crisóstomo como fuente histórica en este pasaje de Sozómeno, vid. Van Nuffelen, P. 2004. Un heritage de paix et de piété. Étude sur les histoires ecclésiastiques de Socrate et de Sozomène: 493. Lovaina: Peeters. Para la culpabilidad de los demonios en las fuentes tardo-antiguas, Brown, P. 1972. Religion and Society in the Age of Saint Augustine: 131-132. Londres: Faber and Faber. Vid. también Lib., Or. I.252; XIX, 29; XXII, 10.

28 Uno de los estudios más minuciosos sobre los atributos y características de esta diosa es Johnston, S.I. 1999. Restless Dead. Encounters between the Living and the Dead in Ancient Greece: 203249. Berkeley-London: University of California Press.

29 Johnston, S.I. 1991. "Crossroads". ZPE 88: 217-224.

30 Farnell, L.R. 1896. "Hecate in Art", en Farnell, L.R. (ed.), The Cults of the Greek States: 36-54. Oxford: Clarendon Press; Harden, D.B. 1927. "A Series of Terracottas Representing Artemis, Found at Tarentum". JHS 47.1: 93-101, especialmente 95-96; García Teijeiro, M. 2005. "De maga a bruja. Evolución de la hechicera en la Antigüedad clásica”, en Pedregal Rodríguez, M.A. y González, M. (eds.), Venus sin espejo: imágenes de mujeres en la Antigüedad clásica y el cristianismo primitivo: 33-53, especialmente pp. 37-38. Oviedo: KRK Ediciones; Johnston, S.I. 1998. "Hekate". NPauly 5: 267-270.

31 Para el sincretismo de Hécate con otras divinidades, véase Calvo Martínez, J.L. 1992. "La Diosa Hécate: un paradigma de sincretismo religioso del helenismo tardío". Florentia lliberritana 3: 71 82; Faraone, C. 1997. "Hymn to Selene-Hecate-Artemis from a Greek Magical Handbook (PGM 2714-83)", en Kiley, M. (ed.), Prayer from Alexander to Constantine: 195-199. Londres: Routledge; Rabinowitz, J. 1997. “Underneath the Moon: Hekate and Luna”. Latomus 56: 535-543. que Sozómeno parece precaverse de la escasa verosimilitud de este pasaje mediante el empleo del verbo rector $\phi \alpha \sigma i$ con sentido impersonal, ${ }^{32}$ es cierto que estas líneas encajan perfectamente en lo que se ha dado en llamar letteratura dell'irrazionale,$^{33}$ esto es, una tendencia a argumentar acontecimientos violentos o que marcan un tránsito mediante la inserción de pasajes en los que lo sobrenatural juega un papel preponderante. En el caso de las novedades introducidas por Sozómeno en su relato (las letanías que el obispo Flaviano hace entonar a jóvenes constantinopolitanos y la aparición del fantasma gigante), éstas no deben interpretarse como desviaciones conscientes o desacuerdos doctrinales respecto a su fuente primaria, Juan Crisóstomo, sino como licencias literarias destinadas a reforzar la posición de Flaviano como único obispo legítimo en el marco del cisma meleciano por su meritoria maniobra para aplacar la ira imperial y para enfatizar la imagen de Teodosio como emperador ortodoxo, un elemento importante en un autor alejado de las discusiones doctrinales como Sozómeno, cuyo máximo interés residía en subrayar la importancia de atenerse a la ortodoxia nicena. ${ }^{34}$

Teodoreto de Ciro. HE V.20; Historia de los Monjes de SIRIA 13.7

El testimonio relativo a la revuelta de las estatuas de Teodoreto de Ciro aparece en dos de sus obras (Historia Eclesiástica V.20, Historia de los Monjes de Siria 13.7), y es problemático por diversos motivos. En primer lugar, porque en HE V.20 ubica la revuelta de las estatuas tras el famoso episodio de la masacre en el hipódromo de Tesalónica en el 390. ${ }^{35}$ Este importante lapsus cronológico de Teodoreto hace dudar de la fiabilidad del relato del obispo de Ciro, si bien parte de la crítica moderna considera que no se trata de un error cronológico sino de una consciente manipulación de los hechos para acomodar la narración de los acontecimientos a uno de los objetivos de su Historia Eclesiástica' en particular al aspecto referido al progresivo desarrollo del concepto de la pietas cristiana del emperador. ${ }^{36}$ Teodosio, según querría hacernos creer Teodoreto, pasó de ceder ante la ira en el episodio de Tesalónica a contener su cólera y conceder el perdón a Antioquía gracias a la mediación de Ambrosio de Milán (HE V.20.10). Así pues, ya sea error cronológico o interesada manipulación del orden de acontecimientos, este hecho debe alertarnos

32 Van Nuffelen, P. 2004: 245: “Sozomène semble délibérément avoir essayé de masquer sa dépendance des sources narratives".

33 Vid. Guidorizzi, G. 1995. "La letteratura dell'irrazionale", en Cambiano, G.; Canfora, L. y Lanza, D. (eds.), Lo Spazio Letterario della Grecia Antica, vol. II: 591-627. Roma: Salerno. También Reardon, B.P. 1971. Courants littéraires grecs de lle et IIle siècles après J.-C.: 237-243. París: Les Belles Lettres.

34 Van Nuffelen, P. 2004: 77-78.

35 Vid. Teodoreto HE V.17-18. Acerca del episodio de Tesalónica y cómo marcó la relación entre Teodosio y Ambrosio, Liebeschuetz, J.H.W.G. y Hill, C. 2005: 262-269; McLynn, N. 1994: 106-111.

36 Martin A.; Canivet, P.; Bouffartigue, J. et al. 2009. Histoire Ecclésiastique. Livres III-V: 419, n. 3. París: Editions du Cerf: "il a choisi d'inverser le récit des deux événements, en plaçant l'émeute d' Antioche après le massacre de Thessalonique dans le contexte duquel elle est d'abord citée, ce qui lui permet de montrer, fidèle à son propos, les progres de la piété impériale". 
sobre la fiabilidad de Teodoreto, cuya tendencia a las exageraciones retóricas rebaja la credibilidad histórica de sus comentarios y otorga en ocasiones un tono panfletario a sus escritos. ${ }^{37}$

En segundo lugar, los dos pasajes que dedica a la revuelta de las estatuas presentan algunas diferencias de contenido. En su Historia de los Monjes de Siria 13.7, el tono encomiástico inherente a este tipo de composiciones condiciona el relato. De este modo, en su semblanza hagiográfica del monje Macedonio, ${ }^{38}$ Teodoreto destaca el hecho de que Macedonio bajara de los montes cercanos a Antioquía para interceder por la ciudad y que los emisarios imperiales, Cesario y Elébico, lo reconocieran al instante y que lo honraran abrazando sus rodillas. El discurso en siriaco de Macedonio fue traducido y convenció a los emisarios por su argumentación simple: las estatuas atacadas pueden ser reconstruidas, pero si el emperador condena a muerte a los culpables no podrá restaurar sus vidas. Sin embargo, en la Historia Eclesiástica, el reconocimiento por parte de los emisarios imperiales no es instantáneo, sino que precisaron que los guías locales les advirtieran de quién era ese anciano que les agarraba de la clámide y en lengua siriaca les pedía que descabalgaran para hablar con él (V.20.5). A pesar de ser un monje completamente ignorante de las Escrituras, Macedonio citó el famoso pasaje de Génesis 1:26 (creación del hombre a imagen y semejanza de Dios) para pedir al emperador que no destruyera esas imágenes divinas que son los hombres. ${ }^{39}$ La discordancia en esta parte del relato se puede explicar por una cuestión de género literario: el relato hagiográfico de la Historia de los Monjes de Siria requería un mayor énfasis en la dimensión encomiástica del personaje alabado, mientras que la Historia Eclesiástica, dirigida a una audiencia diferente, ${ }^{40}$ resaltaba la parrhesía del monje así como la bondad del emperador Teodosio.

Con todo, en ambos pasajes sobre la revuelta de las estatuas, Teodoreto persiste en el esquema "pro-meleciano" ideado por Crisóstomo, ${ }^{41}$ si bien haciendo hincapié en el papel de los monjes de Siria en lugar de la labor del obispo Flaviano. Juan Crisóstomo también había alabado la intervención de los monjes en los días posteriores a la revuelta pero mantuvo en el anonimato la identidad del monje que había intervenido con tal parrhesía ante Cesario y Elébico (Hom. XVII, PG, 49, 173): "Se dice que uno de ellos realizó una intervención llena de filosofía: "Las estatuas derribadas

37 Van der Paverd, F. 1991: 24, 39-40, 59.

38 Canivet, P. y Leroy-Molinghen, A. 1997. Théodoret de Cyr. Histoire des Moines de Syrie: 480-484. París: Editions du Cerf; Teja, R. 2008. Teodoreto de Ciro. Historia de los Monjes de Siria: 121-128. Madrid: Trotta.

39 Sobre la exégesis de Gen 1:26 en Teodoreto, vid. Viciano, A 1996. "El hombre, imagen de Dios (Gen 1,26) en las obras exegéticas de Teodoreto de Ciro", en Casciaro, J.M. et al. (eds.), Esperanza del hombre y revelación bíblica: 200-214. Navarra: Eunsa.

40 Canivet, P. 1977. Le monachisme syrien selon Theodoret de Cyr: 235-253. París: Beauchesne; Krueger, D. 1997. “Typological Figuration in Theodoret of Cyrrhus' Religious History and the art of postbiblical narrative". Journal of Early Christian Studies 5.3: 394-395.

41 Martin, A. 2004. ' $L$ ' église d'Antioche dans l'Histoire Ecclésiastique de Théodoret". Topoi suppl. 5: 505 habla de la Historia Eclesiástica de Teodoreto como "une histoire entièrement nicéenne de I' Église d' Antioche". Vid. también Canivet, P. y Leroy-Molinghen, A. 1997: 75-81. han sido erigidas de nuevo, y han recobrado su forma original, y lo ocurrido tuvo una rápida reparación. En cambio, si vosotros asesináis a la imagen de Dios, ¿cómo podréis citar de nuevo al que se equivocó? ¿Cómo resucitaréis a los muertos y devolver sus almas a sus cuerpos?" También les dijeron muchas cosas sobre el juicio". Es evidente que la cuestión radica en determinar los motivos por los que Crisóstomo no quiso dar el nombre del monje en cuestión. La explicación se encuentra en un ligero desencuentro entre el obispo Flaviano y Macedonio. Así, según Teodoreto Historia de los Monjes de Siria 13.4-5, Macedonio fue ordenado sacerdote por el obispo Flaviano sin conocimiento de causa. Enterado de lo que había sucedido y temeroso de tener que abandonar su estilo de vida, el viejo monje se enojó tanto que persiguió a Flaviano con la intención de pegarle con su bastón. Esta representación de la difícil relación entre el cristianismo urbano y el rural justificaría el anonimato de Macedonio en el relato de Crisóstomo y la ausencia de toda alusión al obispo Flaviano en los pasajes de Teodoreto relativos a la revuelta de las estatuas. Así, resulta cuando menos curioso que en otros dos pasajes de Teodoreto (Historia de los Monjes de Siria 2.16; 7.6-8) se explicita que el entonces sacerdote Flaviano solicitó la ayuda de los monjes de Siria para hacer frente a las medidas adoptadas por el emperador arriano Valente. En ambas ocasiones, la petición de ayuda de Flaviano y otro sacerdote, Diodoro, fue atendida por los monjes Juliano Sabas y Afraates. En el caso de Macedonio, sin embargo, Teodoreto no sigue ese patrón narrativo y omite la mención de Flaviano dadas las discordancias entre Macedonio y Flaviano, y simplemente comenta que Macedonio bajó del monte sin que nadie se lo pidiera (13.7).

Teodoreto, en consecuencia, sigue desarrollando el esquema "pro-meleciano" que comienza con las homilías de Juan Crisóstomo, pero lo aborda desde la perspectiva del papel del monacato. ${ }^{42}$ De este modo, la salvación de Antioquía se debió, en opinión de Teodoreto, a la intervención de Macedonio y a la bondad del emperador (V.20.9), ignorando así el papel desempeñado por el obispo Flaviano. Con esta estrategia narrativa en mente, Teodoreto desarrolla argumentos ya esbozados por Crisóstomo, pero cambiando la identidad de los protagonistas. Así, la oportuna cita de Macedonio de Génesis 1:26 a propósito del hombre como obra hecha a imagen y semejanza de Dios tiene su paralelo en la argumentación del discurso de Flaviano ante el emperador Teodosio en la homilía 21, en la que el obispo advierte al emperador en términos similares, e incluso inserta un exemplum histórico en el que se compara la benevolencia de Constantino con la que Teodosio debería tener (Hom. XXI, PG 49.216): "Se dice que, en una ocasión en que una estatua suya fue apedreada, muchos excitaban al feliz Constantino para que fuera contra los insolentes y los castigara, diciéndole que los que habían lanzado las piedras le habían herido todo su rostro. Tras palparse el rostro con las manos y esbozar una tranquila sonrisa, dijo: No veo que haya herida alguna en mi rostro, sino que la cabeza está sana, todo mi rostro sano. Y aquellos, ruborizados y avergonzados retiraron ese mal consejo".

42 Para la relación de Teodoreto con el monacato la obra de referencia sigue siendo Canivet, P. 1977. 


\section{CONCLUSIONES}

Con la excepción de la breve alusión contenida en la epístola 74 de Ambrosio de Milán, las demás fuentes cristianas que trataron la revuelta de las estatuas se concentran en tres aspectos principales cuyo contenido y tratamiento metodológico, a pesar de estar amoldado al género literario y a la ideología de cada autor, es coherente y persigue objetivos comunes. Así, en primer lugar, Crisóstomo (Hom. XXI, PG 214-215), Sozómeno (HE VII.23) y Teodoreto (Historia de los Monjes de Siria 13.7) culpabilizaron de los incidentes violentos a un demonio que manipuló a los antioquenos o, como en el caso de la innovación introducida por Sozómeno, a un ente sobrenatural cuyas atribuciones recuerdan a la diosa Hécate. Amén de ser un recurso retórico destinado a exonerar a los ciudadanos de la responsabilidad de la algarada, la inclusión del elemento sobrenatural es parte del género y del Zeitgeist de la tardo-antigüedad. ${ }^{43}$ En el ámbito de la literatura pagana, por ejemplo, abundan los relatos de acontecimientos sobrenaturales que simbolizan y predicen la desaparición del Imperio ante la acumulación de poder del cristianismo y la negligencia en el cumplimiento de los ritos tradicionales. ${ }^{44}$ Por su parte, el cristianismo encontró en el recurso a lo sobrenatural y a la mención al demonio una forma de combatir un nuevo enemigo y probar la fortaleza espiritual del holy man, algo que ocurrió muy especialmente en el caso de los monjes. ${ }^{45}$ Tal y como expresa Cyril Mango, "demonology contributed very powerfully to the spread of the Christian religion". ${ }^{46}$

En segundo lugar, el tratamiento de la revuelta de las estatuas ofreció un inmejorable marco histórico a las fuentes cristianas para delinear la figura histórica del emperador Teodosio en relación al cristianismo. El retrato del emperador como un cristiano que debe someterse a la voluntad divina sirve para sustentar el nuevo orden que se estaba implantando. ${ }^{47}$ La presencia de Teodosio en los relatos de Ambrosio, Crisóstomo y Teodoreto tiene una función simplemente instrumental, limitándose a ser el espectador pasivo que admira la parrhesía del obispo cristiano o que cede ante la libertad de palabra del monje Macedonio. ${ }^{48}$

Por último, los relatos de Juan Crisóstomo, Sozómeno y Teodoreto están vertebrados por la puesta en escena de un plan meleciano que ayuda a consolidar la figura del

$43 \quad$ Especialmente relevante para este aspecto es el trabajo de Cracco Ruggini, L. 1977. "The Ecclesiastical Histories and the Pagan Historiography: providence and miracles". Athenaeum 55: 107-126.

44 Lib., Or. 19.30; Zósimo IV.21. Vid. también Chadwick, H. 1984. "Oracles of the End in the Conflict of Paganism and Christianity in the Fourth Century", en Luchhesi, E. y Saffrey, H.D. (eds.), Mémorial A-J. Festugiere. Antiquité païenne et chrétienne: 125-129. Ginebra: P. Cramer.

45 Festugière, A.-J. 1961. Les moines d'Orient, vol. I: 23-39. París: Edition du Cerf.

46 Mango, C. 1994. Byzantium: the Empire of the New Rome: 215. Londres: Phoenix.

47 Léase, en este sentido, Agustín, De Civitate Dei 5.26, o Teodoreto HE 5.18.23.

48 Barterlink, G.J.M. 1970. “Quelques observations sur parrhésia dans la littérature paleochrétienne", en Mohrmann, C. et al. (eds.), Gracietas et Latinitas. Christianorum Primaeva. Studia ad sermonem christianum primaevum pertinentia: 7-57. Nimega: Dekker \& van de Vegt; Liebeschuetz, J.H.W.G. 2011: 43-54. Scarpat, G. 2001. Parrhesia greca, parrhesia cristiana. Brescia: Paideia. obispo Flaviano como el legítimo obispo de Antioquía en un periodo de disputas en el seno de la Iglesia de la capital siria. Las discordancias entre el relato de Crisóstomo y el de Teodoreto no pueden considerarse como un enfrentamiento doctrinal, sino que responden a un mismo objetivo -la defensa y propaganda de la facción meleciana- desde distintas perspectivas.

La revuelta de las estatuas fue un evento cuya trascendencia no ha encontrado el impacto esperado en la bibliografía moderna. La confluencia de factores económicos (el impuesto que generó la protesta), religiosos (cisma meleciano) y políticos (delicada situación del Imperio por las crisis económicas y el elevado coste social de las guerras contra los bárbaros) ${ }^{49}$ convirtieron la asonada antioquena en un hecho histórico del que se valieron autores contemporáneos y posteriores para articular una defensa del melecianismo y para configurar una imagen arquetípica del emperador como obediente cristiano y admirador de la parrhesía de las figuras cristianas.

\section{BibLIOgRAFÍA}

Ashbrook-Harvey, S. 2000. "Antioch and Christianity", en C. Kondoleon (ed.), Antioch, The Lost Ancient City: 38-49. Princeton: Princeton University Press.

Auski, P. 1995. Christian Plain Style: The Evolution of an Spiritual Ideal. Montreal: McGill-Queen's University Press.

Barterlink, G.J.M. 1970. “Quelques observations sur parrhésia dans la littérature paleochrétienne", en Mohrmann, C. et al. (eds.), Gracietas et Latinitas. Christianorum Primaeva. Studia ad sermonem christianum primaevum pertinentia: 7-57. Nimega: Dekker \& van de Vegt.

Brottier, L. 2004. "Jean Chrysostome. Un pasteur face à des demi-chrétiens". Topoi 5: 439-457.

Brown, P. 1972. Religion and Society in the Age of Saint Augustine. Londres: Faber and Faber.

Brown, P. 1992. Power and Persuasion in Late Antiquity. Towards a Christian Empire. Madison: University of Wisconsin Press.

Browning, R. 1952. "The riot of A.D. 387 in Antioch. The role of the theatrical Claques in the Late Empire". Journal of Roman Studies 42: 13-20.

Bruun, P. 1976. "Notes in the transmission of Imperial Images in Late Antiquity", en Ascani, K. et al. (eds.), Studia Romana in Honorem Petri Krarup septuagenarii: 122-131. Odense: Odense University Press.

Buenacasa, C. 1997. "La figura del obispo y la formación del patrimonio de las comunidades cristianas según la legislación imperial del reinado de Teodosio I". Studia Ephemeridis Augustinianum 58.1: 121-139.

Calvo Martínez, J.L. 1992. "La Diosa Hécate: un paradigma de sincretismo religioso del helenismo tardío". Florentia Iliberritana 3: 71-82.

Canivet, P. 1977. Le monachisme syrien selon Theodoret de Cyr. París: Beauchesne.

Canivet, P. y Leroy-Molinghen, A. 1997. Théodoret de Cyr. Histoire des Moines de Syrie. París: Editions du Cerf.

Cavallera, F. 1905. Le schisme d'Antioche. París: A. Picard.

Chadwick, H. 1984. "Oracles of the End in the Conflict of Paganism and Christianity in the Fourth Century", en Luchhesi, E. y Saffrey, H.D. (eds.), Mémorial A-J. FESTUGIERE. Antiquité païenne et chrétienne: 125-129. Ginebra: P. Cramer.

Chadwick, H. 2001. The Church in Ancient Society. From Galilee to Gregory the Great. Oxford: Oxford University Press.

Chesnut, G. 1977. The first Christian Histories. Eusebius, Socrates, Sozomen, Theodoret, and Evagrius. París: Beauchesne.

49 Williams, S. y Friel, G. 1994. Theodosius. The Empire at bay: 91-115. Londres: Routledge. 
Cracco Ruggini, L. 1977. "The Ecclesiastical Histories and the Pagan Historiography: providence and miracles". Athenaeum 55 107-126.

Depeyrot, G. 1996. Crisis e inflación entre la Antigüedad y la Edad Media. Barcelona (trad.): Crítica.

De Sainte Croix, G.E.M. 1988. La lucha de clases en el mundo griego antiguo. Barcelona (trad.): Crítica.

Downey, G. 1961. A History of Antioch in Syria: from Seleucus to the Arab Conquest. Princeton: Princeton University Press.

Downey, G. 1962. Antioch in the age of the Theodosius the Great. Oklahoma: University of Oklahoma Press.

Faraone, C. 1997. "Hymn to Selene-Hecate-Artemis from a Greek Magical Handbook (PGM 2714-83)", en Kiley, M. (ed.), Prayer from Alexander to Constantine: 195-199. Londres: Routledge.

Farnell, L.R. 1896. "Hecate in Art”, en Farnell, L.R. (ed.), The Cults of the Greek States: 36-54. Oxford: Clarendon Press.

Festugière, A.-J. 1961. Les moines d’Orient, vol. I. París: Edition du Cerf.

García Fernández, J.M. 1995. "La autocefalia de la Iglesia chipriota, una consecuencia del cisma del siglo IV en la cristiandad de Antioquía". Espacio, Tiempo y Forma Serie II, Ha. Antigua 8: 501-505.

García Teijeiro, M. 2005. “De maga a bruja. Evolución de la hechicera en la Antigüedad clásica”, en Pedregal Rodríguez, M.A. y González, M. (eds.), Venus sin espejo: imágenes de mujeres en la Antigüedad clásica y el cristianismo primitivo: 33-53. Oviedo: KRK Ediciones.

Guidorizzi, G. 1995. "La letteratura dell'irrazionale", en Cambiano, G.; Canfora, L. y Lanza, D. (eds.), Lo Spazio Letterario della Grecia Antica, vol. II: 591-627. Roma: Salerno.

Guinot, J.N., 2001. "L'Histoire du siège d'Antioche relue par Jean Chrysostome. Idéalisation ou déformation intentionelle?", en Cabouret, B.; Gatier, P.L. y Saliou, C. (eds.), Antioche de Syrie. Histoire, images et traces de la ville Antique: 459-479. Lyon: De Boccard.

Harden, D.B. 1927. "A Series of Terracottas Representing Artemis, Found at Tarentum". JHS 47.1: 93-101.

Johnston, S.I. 1991. "Crossroads". ZPE 88: 217-224.

Johnston, S.I. 1998. “Hekate”. NPauly 5: 267-270.

Johnston, S.I. 1999. Restless Dead. Encounters between the Living and the Dead in Ancient Greece. Berkeley-London: University of California Press.

King, N.Q. 1961. The Emperor Theodosius and the establishment of Christianity. Londres: SCM.

Krueger, D. 1997. "Typological Figuration in Theodoret of Cyrrhus" Religious History and the art of postbiblical narrative". Journal of Early Christian Studies 5.3: 393-419.

Leppin, H. 1999. "Steuern, aufstand und rhetoren: der antiochener steueraufstand von 387 in christlicher und heidnischer deutung", en Brandt, H. (ed.), Gedeutete Realität. Krisen, wirklichkeiten, interpretationem (3.-6. Jh. n.Chr.): 103-123. Stuttgart: F. Steiner.

Liebeschuetz, J.H.G.W. 1959. "The finances of Antioch in the fourth century". Byzantinische Zeitschrift, 52.2: 344-356.

Liebeschuetz, J.H.G.W. 1972. Antioch: city and imperial administration in the later Roman Empire: 215. Oxford: Oxford University Press.

Liebeschuetz, J.H.W.G. y Hill, C. 2005. Ambrose of Milan. Political Letters and Speeches. Liverpool: Liverpool University Press.

Liebeschuetz, J.H.W.G. 2011. Ambrose and John Chrysostom. Clerics between Desert and Empire. Oxford: Oxford University Press.

Malosse, P.L. 2007. "Comment arrêter un massacre: une leçon de rhétorique appliquée (Libanios, Discours XIX)". Revue des Études Grecques 120: 107-140.

Mango, C. 1994. Byzantium: the Empire of the New Rome. Londres: Phoenix.

Maraval, P. 2009. Théodose le Grand: le pouvoir et la foi. París: Fayard.

Martin, A. 2004. 'L' église d'Antioche dans I'Histoire Ecclésiastique de Théodoret". Topoi 5: 481-506.

Maxwell, J. 2006. Christianization and Communication in Late Antiquity. John Chrysostom and his Congregation at Antioch. Cambrige: Cambridge University Press.
Mayer, W. 2005. The homilies of St. John Chrysostom, provenance: reshaping the foundations. Roma: Pontificio Istituto orientale.

McLynn, N. 1994. Ambrose of Milan. Church and Court in a Christian Capital. Berkeley: University of California Press.

Natal Villazala, D. 2010. Fugiamus ergo forum. Ascetismo y poder en Ambrosio de Milán. León: Universidad de León.

Petit, P. 1955. Libanius et la vie municipale à Antioche au IVe siècle après J.C. París: Geuthner.

Pietri, C. 1993. "Les dernières résistances du subordinatianisme et le triomphe de l'orthodoxe nicéenne", en Mayeur, J.M. (ed.), Histoire du Christianisme: 357-398. París: Desclee.

Quiroga Puertas, A.J. 2007. La retórica de Libanio y de Juan Crisóstomo en la revuelta de las estatuas. Salerno: Helios.

Quiroga Puertas, A.J. 2014. "Hecuba revisited. Euripidean Echoes in Libanius Or. 22.22". GRBS 54.1: 69-86.

Rabinowitz, J. 1997. "Underneath the Moon: Hekate and Luna". Latomus 56: 535-543.

Rapp, C. 2005. Holy Bishops in Late Antiquity: the nature of Christian leadership in an age of transition. Berkeley: University of California Press.

Reardon, B.P. 1971. Courants littéraires grecs de Ile et Ille siècles après J.-C.. París: Les Belles Lettres.

Scarpat, G. 2001. Parrhesia greca, parrhesia cristiana. Brescia: Paideia. Shepardson, C. 2007. "Controlling Contested Places: John Chrysostom's Adversus ludaeos Homilies and the Spatial Politics of Religious Controversy". Journal of Early Christian Studies 15.4: 483-516.

Soler, E. 1997. "Evêque et pasteurs à Antioche sous l'empereur Théodose: I'engagement chrétien dans la défense de la cité après la séditions des statues (387)", en Istituto Patristico Augustinianum (ed.), Vescovi e pastori in epoca Teodosiana. XXV Incontro di studiosi dell'antichità cristiana: 461-467. Roma: Istituto Patristico Augustinianum.

Soler, E. 2001. "Utilisation de l'historie de l'Église d'Antioche au IVème siècle par Jean Chrysostome dans les débuts de sa prédication", en B. Pouderon y Y. M. Duval (eds.), L'Historiographie de l'Église des premiers siècles: 499-510. París: Beauchesne.

Sotomayor, M. 2003. "El cristianismo en Oriente”, en Fernández Ubiña, J. y Sotomayor, M. (eds.), Historia del Cristianismo: 815-868. Madrid: Trotta.

Spuntarelli, C. 2010. “Didascalia e potere episcopale ad Antiochia nell' ideologia dei panegirici di Giovanni Crisostomo". ASE 27.1: 77-100.

Stewart, P. 1999. "The destruction of Statues in Late Antiquity", en Miles, R. (ed.), Constructing Identities in Late Antiquity: 159-189.

Teja, R. 2008. Teodoreto de Ciro. Historia de los Monjes de Siria: 121128. Madrid: Trotta.

Thélamon, Fr. 2010. "Théodose, I' État et les religions", en Delage, P.-G. (ed.), Ambroise de Milan et les défis du politique: 25-56. Royan: Caritas Patrum.

Valedicius, A. 2000. "Les 24 homélies De Statuis de Jean Chrysostome. Recherches nouvelles", Revue des Études Augustiniennes et Patristiques 46: 83-91.

Van der Paverd, F. 1991. St. John Chrysostom. The homilies on the Statues. Roma: Institutum Studiorum Orientalium.

Van Nuffelen, P. 2004. Un heritage de paix et de piété. Étude sur les histoires ecclésiastiques de Socrate et de Sozomène. Lovaina: Peeters.

Viciano, A. 1996. "El hombre, imagen de Dios (Gen 1,26) en las obras exegéticas de Teodoreto de Ciro", en Casciaro, J.M. et al. (eds.), Esperanza del hombre y revelación bíblica: 200-214. Navarra: Eunsa.

Will, E. 2000. "Antioche, la métropole de l'Asie", en Nicolet, C.; Ilbert, R. y Depaule, J.C. (eds.), Mégapoles méditerranéennes. Géographie urbaine rétrospective: 482-491. París: Maissonneuve et Larose.

Williams, S. y Friel, G. 1994. Theodosius. The Empire at bay. Londres: Routledge.

Wisse, J. 1989. Ethos and Pathos from Aristotle to Cicero. Amsterdam: Hakkert. 